\title{
Analysis of Vitamin Composition of Alternanthera tenella Colla (Amaranthaceae)
}

\author{
K. Ramani \\ Assistant Professor, Plant Biology and Plant Biotechnology Department, Srimathi Devkunvar Nanalal Bhatt Vaishnav College for Women \\ (Autonomous), Chennai - 600044, Tamil Nadu, India. Contact No: 8144678400, Email : kkramanicc[at]yahoo.com
}

\begin{abstract}
Vitamin is an organic compound required by an organism as a vital nutrient from the diet in limited amounts when it is not synthesized in sufficient quantities by the organism. Plants are the richest bio-resources of food supplements and modern medicine. They are good source of vitamins exert specific medicinal action in the human diet and may be used in response to specific health problems. The vitamin compositions of Alternanthera tenella Colla were analyzed. The result shows that the $\beta$ carotene, carotenoids, vitamin $B_{1}$ and $B_{12}$ were present in more amounts.
\end{abstract}

Keywords: Alternanthera tenella, traditional, nutritional, vitamins, medicinal plant

\section{Introduction}

Plants can provide food, nutrition and medicine (Block, 1941 and 1952). They are used globally by the indigenous and marginal communities for cure various diseases. Wild available plants are high in bioactive secondary compounds. Their medicinal value is due to the presence of certain chemical substances. They produce definite physiological action on human body. The nutritional anemia occurs when one or more of the nutrients necessary for RBCs production, shortage of iron, cobalamin and folic acid (Dudek, 1997).

Vitamins are essential for the normal growth maintenance and functioning to eradicate deficiency diseases. They are fat or water soluble. They need in very small amount, help regulate and support chemical reactions. Thermal processing can also enhance the bioavailability of thiamin, vitamin $\mathrm{B}_{6}$, niacin and folate. They are essential to maintain good vision and assists in immune reactions. International Unit is a crude measure of vitamins based on the growth rate of animals. Carotenoids are pigment substance in plants that can form vitamin A. Beta-carotene is a pro-vitamin that reduces the rate of heart disease. Lutein protects from various eye disease. They acted as anti-oxidants, anti-allergic, anti-aging and anti-cancer agents. Thiamine is a crystalline compound, which occur naturally in free-state or complex. It is soluble in water and destroyed by heat or oxidation. It needs for each day to maintain health. Riboflavin is a photosensitive vitamin, which destroy by light and excessive cooking. It is essential for wound heals; maintain cellular antioxidant and antibody production. Pyridoxine helps to synthesize non-essential amino acids, making antibodies and RBCs. It is vital to multiplication of all cells and enhanced memory. Cyanocobalamin contains the mineral cobalt used as cofactor and protective medicine. It needs for fertility, cell growth and division. Ascorbic acid is a white crystalline substance acts as an excellent antioxidant. It is essential for resistance, absorptions of iron, calcium and folacin. It helps to cure cancer and heart disease. Human lacks the enzyme necessary to synthesis vitamin C. It replenished every day and protected against harmful effects of toxic chemicals. It is easily destroyed by oxidation, light and heat. Tocopherol is essential for normal reproductive function and helps to dilate capillaries (Padayathy et al., 2003). It acts as antioxidant which protecting polyunsaturated fats and other components of the cell membranes from oxidation. Plants can synthesis eight naturally occurring vitamin $\mathrm{E}$ compounds.

Recommended Daily Allowance defined as the average daily dietary intake level. Requirements for adults the carotenoids and beta-carotene are very small amount; thiamine is about $1.4 \mathrm{mg}$; riboflavin is $1.3 \mathrm{mg}$ for men and $1.1 \mathrm{mg}$ for women; pyridoxine is $1-1.7 \mathrm{mg}$; cobalamin is 2-3 $\mu \mathrm{g}$; ascorbic acid is $75 \mathrm{mg}$ for women and $90 \mathrm{mg}$ for men; tocopherol is $15 \mathrm{mg}$. Their requirements depend up on the person's diet, growth, body weight, level of exercise, age and gender (RDA, 1989). The vitamins composition of Alternanthera tenella Colla was analyzed.

\section{Materials and Methods}

\section{Sample Preparation}

Alternanthera tenella Colla (Amaranthaceae) was collected, washed, cut into small pieces and shade dried at room temperature for two weeks. They were ground into fine powder taken for analysis (Mayuranathan, 1992).

Vitamin Analysis (Lawrence Evans, 2012)

\section{Estimation of Vitamin A}

Vitamin A dissolved in n-hexane and diluted with retinyl acetate used as reference standard. The sample mixed with DMSO and n-hexane; heated at $60^{\circ} \mathrm{C}$ and centrifuged at $3000 \mathrm{rpm}$ for $10 \mathrm{~min}$. Standard and sample were separately injected into HPLC. The chromatogram equipped with a $325 \mathrm{~nm}$ detector and $4.6 \mathrm{~mm} \times 15 \mathrm{~cm}$ column $3 \mu \mathrm{m}$ packing L8. The flow rate is $1 \mathrm{~mL}$ per min. The chromatographs and peak areas of the standard and sample were measured. The amount of vitamin A in the sample was calculated using the formula: $0.872 \mathrm{CD}(\mathrm{rU} / \mathrm{rS})$, in which, 0.872 the factor used to convert retinyl acetate, ' $\mathrm{C}$ ' standard concentration, ' $\mathrm{D}$ ' dilution factor used for the assay preparation $(\mathrm{mL}), \mathrm{rU}$ and $\mathrm{rS}$ are peak areas obtained from the sample and the standard. 


\section{International Journal of Science and Research (IJSR) \\ ISSN (Online): 2319-7064 \\ Index Copernicus Value (2015): 78.96 | Impact Factor (2015): 6.391}

\section{Estimation of Beta-Carotene}

The sample mixed with alcohol and $\mathrm{KOH}$, heated for 45 $\mathrm{min}$. The hexane and anhydrous sodium sulfate added and evaporated. The cyclohexane and iodine solution added. Heated $65^{\circ} \mathrm{C}$ for $15 \mathrm{~min}$ and diluted with cyclohexane. The absorbance of the sample was $452 \mathrm{~nm}$. The cyclohexane was used as a blank. The amount of $\beta$-carotene was calculated using the formula, (L/D) (AU/223), ' $\mathrm{L}$ ' is the labeled amount of $\beta$-carotene, ' $D$ ' the concentration of $\beta$ carotene in the sample, 'AU' the absorbance of the sample and ' 223 ' the absorptivity of $\beta$-carotene at $452 \mathrm{~nm}$.

\section{Estimation of Thiamine, Riboflavin and Pyridoxine}

Thiamine, riboflavin, pyridoxine diluted with water, acetonitrile and glacial acetic acid in the proportion (94:5:1). They used as reference standards. They are separately added into the sample, centrifuged and diluted. The standard and sample were injected separately into the HPLC. The chromatogram equipped with a $280 \mathrm{~nm}$ detector and $3.9 \mathrm{~mm} \times 30 \mathrm{~cm}$ column packing L1. The flow rate is $1 \mathrm{~mL}$ per min. The relative retention times of Thiamine, riboflavin and pyridoxine was 1.0, 0.8 and 0.5 . Chromatographs and the peak areas of standard and sample were measured. The amount of pyridoxine, riboflavin and thiamine were calculated using the formula, $25 \mathrm{C}(\mathrm{rU} / \mathrm{rS})$, in which ' $\mathrm{C}$ ' the concentration of the reference standard in the sample, $\mathrm{rU}$ and $\mathrm{rS}$ the peak areas of pyridoxine, riboflavin and thiamine of sample and standard.

\section{Estimation of Cyanocobalamin}

Cyanocobalamin used as reference standard. The sample extracted with water and filtered. The standard and sample were separately injected into the HPLC. Chromatogram equipped with a $550 \mathrm{~nm}$ detector and a $4.6 \mathrm{~mm} \times 15 \mathrm{~cm}$ column $5 \mu \mathrm{m}$ packing L1. The flow rate is $0.5 \mathrm{~mL}$ per min. The water and methanol (65:35) act as mobile phase. The chromatographs and the peak of standard and sample were measured. Cyanocobalamin in the sample was calculated using the formula: $100 \mathrm{C}(\mathrm{rU} / \mathrm{rS})$, in which ' $\mathrm{C}$ ' concentration of reference standard, $\mathrm{rU}$ and $\mathrm{rS}$ the peak areas of sample and standard.

\section{Estimation of Tocopherol}

The $\alpha$-tocopherol diluted in methanol used as reference standard was. The sample $(20 \mathrm{~g})$ mixed with water $(25$ $\mathrm{mL})$, dehydrated alcohol $(25 \mathrm{~mL})$ and $\mathrm{KOH}$ pellets $(3.5 \mathrm{~g})$. They were rinsed with n-hexane. Glacial acetic acid added and filtered. The ergocalciferol and $\alpha$-tocopherol acetate were reference standard solutions. The standard $(100 \mu \mathrm{L})$ and sample $(100 \mu \mathrm{L})$ were separately injected into HPLC. The chromatogram equipped with a $254 \mathrm{~nm}$ detector and 8 $\mathrm{mm} \times 10 \mathrm{~cm}$ column contain $5 \mu \mathrm{m}$ packing $\mathrm{L} 1$. The flow rate is $2 \mathrm{~mL}$ per min. The relative retention time for ergocalciferol is 0.5 and $\alpha$-tocopherol acetate is 1.0. Tailing factor is between 0.8 and 1.2. The chromatographs and peak area of standard and sample were recorded. The amount of tocopherol in the sample was calculated using the formula: $\mathrm{CD}(\mathrm{rU} / \mathrm{rS})$, in which, ' $\mathrm{C}$ ' the concentration of the USP reference standard, 'D' the dilution factor for the sample preparation and $\mathrm{rU}$ and $\mathrm{rS}$ peak responses of sample and standard.

\section{Estimation of Ascorbic Acid}

Ascorbic acid was analyzed by Automate method. The dried sample powder transferred into a flask. The metaphosphoric-acetic acid was added, diluted, centrifuged and pipetted into a conical flask. Titrate with dichlorophenolindophenol color changed into pink. The ascorbic acid in the sample was calculated.

\section{Results and Discussion}

Vitamins have diverse biochemical functions. Vitamins A and $\mathrm{B}_{12}$ are stored in significant amounts in the liver (The Merck Manual). Vitamins $\mathrm{C}$ and $\mathrm{E}$ are not stored and hence needs more consistent intake (Fukuwatari and Shibata, 2008). The body lacks the ability to synthesize vitamins which can be obtained from the food. The result shows that except tocopherol in root, others were present in all other parts. The leaves have more amount of carotenoids $(16.3 \mathrm{mg} / 100 \mathrm{~g})$ and beta-carotene $(12.34$ $\mathrm{mg} / 100 \mathrm{~g}$ ); the flowers have more amount of thiamine $(0.55 \mathrm{mg} / 100 \mathrm{~g})$, riboflavin $(2.14 \mathrm{mg} / 100 \mathrm{~g})$ and pyridoxin $(3.15 \mathrm{mg} / 100 \mathrm{~g})$. Root has amount of cobalamin $(2.56$ $\mathrm{mg} / 100 \mathrm{~g})$ and tocopherol $(0.90 \mathrm{mg} / 100 \mathrm{~g})$. Seed has more amount of Ascorbic acid $(13.4 \mathrm{mg} / 100 \mathrm{~g})$ were below the limit. Compare to RDA, the riboflavin and pyridoxin were showed above the permissible limit and other vitamins were below the limit (Figure 1-4). Alternanthera sessilis leaves contain riboflavin, niacin, ascorbic acid and rich source of carotenes (Gopalan et al., 1971). Vitamins such as $\mathrm{A}, \mathrm{C}$ and $\mathrm{E}$ and other supplementary materials such as carotenoids play important roles in the balance between pro-oxidant and antioxidant system in humans (Patricia Trueman, 2007).

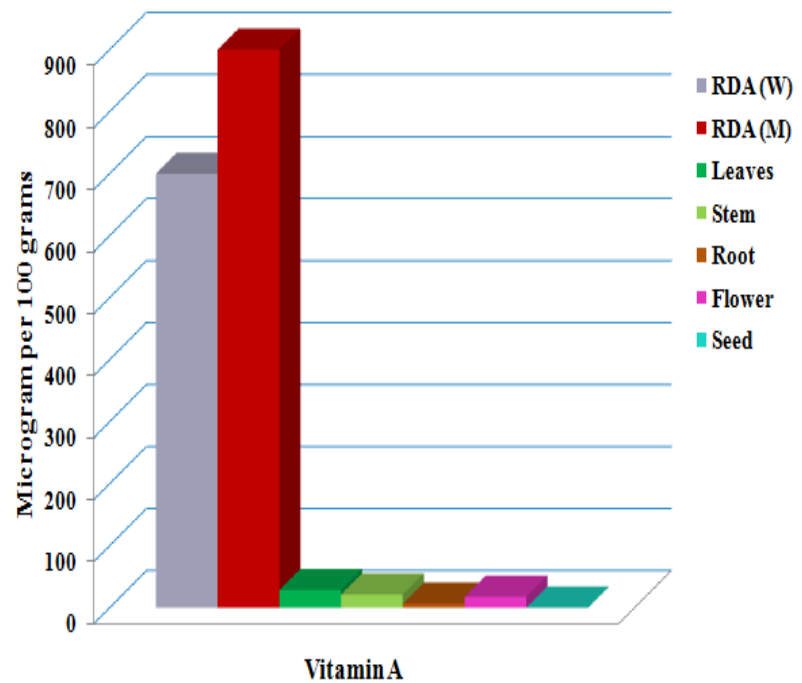

Figure 1: Comparison of Vitamins A content of various parts of $A$. tenella 


\section{International Journal of Science and Research (IJSR) \\ ISSN (Online): 2319-7064}

Index Copernicus Value (2015): 78.96 | Impact Factor (2015): 6.391

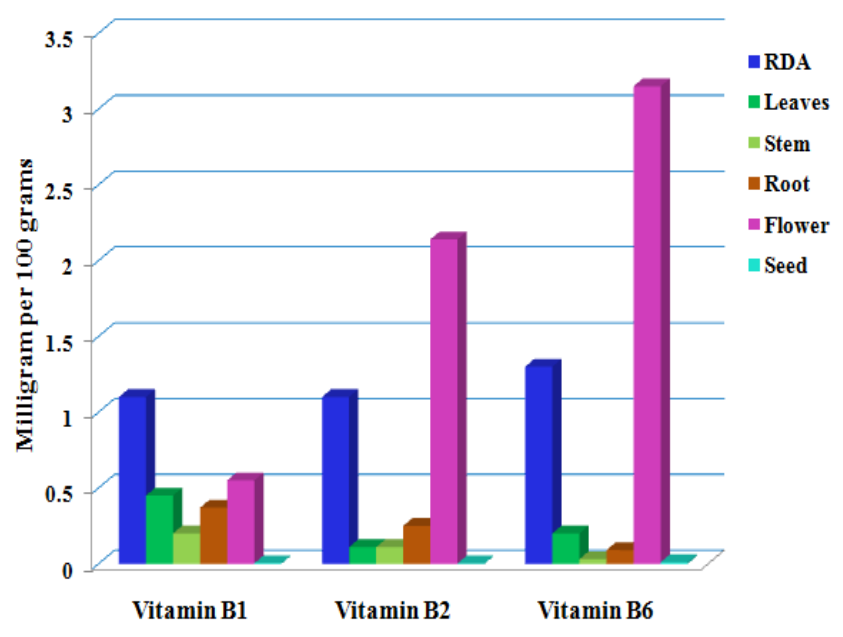

Figure 2: Comparison of Vitamins $\mathrm{B}_{1}, \mathrm{~B}_{2} \& \mathrm{~B}_{6}$ content of various parts of $A$. tenella

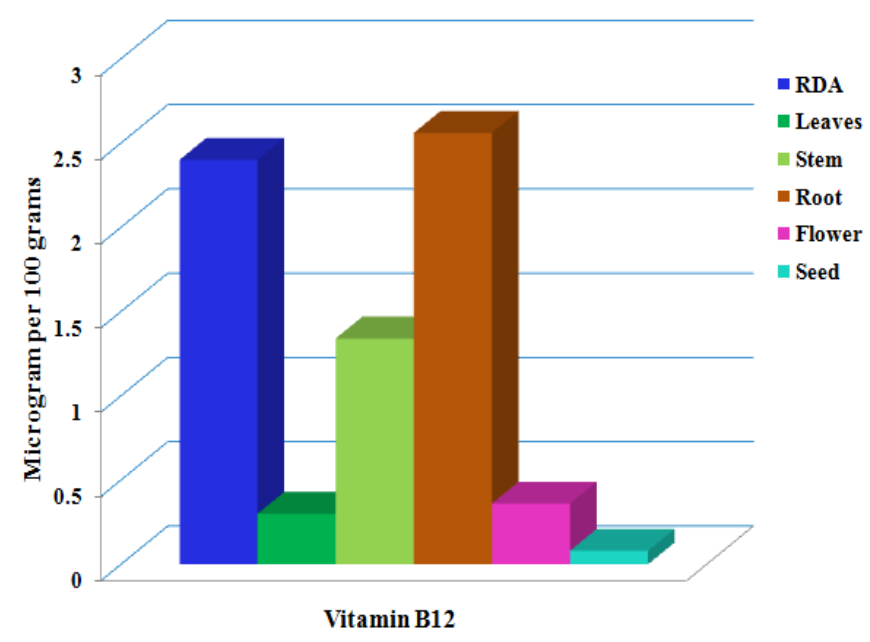

Figure 3: Comparison of Vitamins $\mathrm{B}_{12}$ content of various parts of $A$. tenella

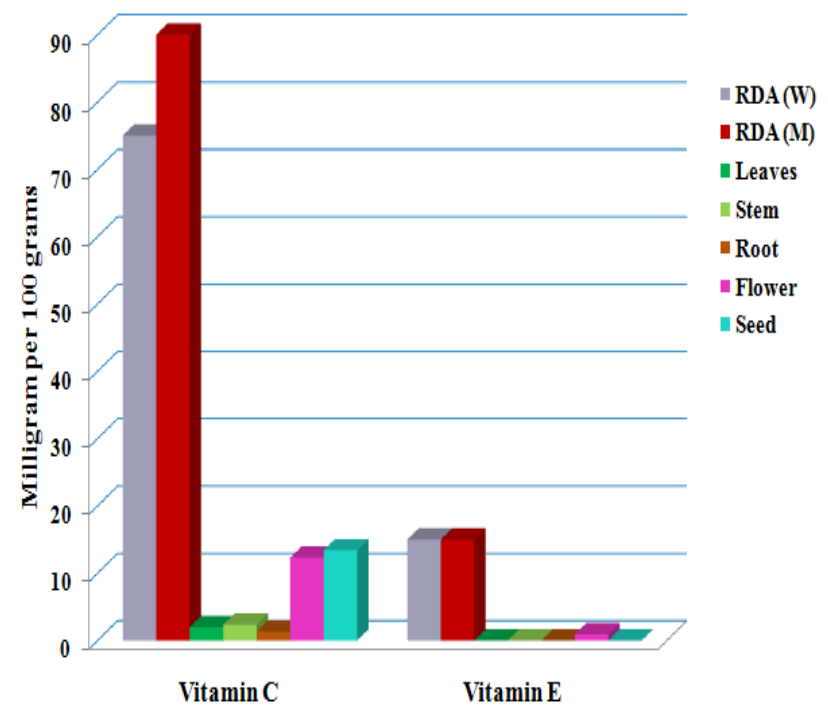

Figure 4: Comparison of Vitamins $\mathrm{C} \& \mathrm{E}$ content of various parts of $A$. tenella

\section{Conclusion}

Vitamin analysis is essential for nutritional properties of wild edible medicinal plants. They act as antioxidants protect cells from free radicals and to cure many diseases. Intake of Alternanthera tenella may help to avoid malnutrition.

\section{References}

[1] Block, R. 1941. Wound healing in higher plants. Bot. Rev. 7.110 - 146.

[2] Block, R. 1952. Wound healing in higher plants II. Bot. Rev. 10. 655 - 677.

[3] Dudek, S. G. 1997. Nutrition Handbook for Nursing Practice. Philadelphia: Lippincott-Raven.

[4] Fukuwatari T and Shibata K (2008). "Urinary watersoluble vitamins and their metabolite contents as nutritional markers for evaluating vitamin intakes in young Japanese women". J. Nutr. Sci. Vitaminol. 54 (3): $223-9$.

[5] Gopalan, C., Rama Sastri, B. V. and Balasubramanian, S. C. 1971. Nutritive value of Indian foods. National Institute of Nutrition, Hyderabad, ICMR, New Delhi (Revised by Narasinga Rao, B. S, Deosthale, Y. G. and Pant, K. C. 1989, p.50.

[6] Mayuranathan, P. V. 1992. The Flowering Plants of Madras City and its Immediate Neighbourhood. Bull Madras Govt. Mus. N. S. 2: 1 - 345, tt. 1 - 38.

[7] Padayathy, S., Katz, A., Wang, Y., Eck, P., Kwon, O., Lee, J., Chen, S., Corpe, C., Dutta, A., Dutta, S. and Levine, M., 2003. Vitamin C as an antioxidant evaluation of its role in disease prevention. J. AM. Coll. Nutr., 33:18-35.

[8] Recommended Daily Allowances, 1989, $10^{\text {th }}$ ed., Food Nutrition Board, Natl. Res., Council National Academy Press, Washington, DC.

[9] Patricia Trueman, 2007. Nutritional Biochemistry, MJP Publishers, Chennai 600 005. ISBN 978-818094-031-6 